\title{
Impacto ambiental de las aguas residuales de la Planta El Pino Programa Moscamed, sobre las comunidades de influencia en El Cerinal, Barberena, Santa Rosa
}

\author{
Oscar Roberto Zaldaño Hernández \\ ozom30@gmail.com \\ Ingeniero Agrónomo y Maestro en Ciencias en Desarrollo Rural y Cambio Climático \\ Planta El Pino, Programa Moscamed, Guatemala
}

Fecha de recepción: 09/04/2018

Fecha de aceptación: 02/07/2018

\begin{abstract}
Resumen
La mosca del Mediterráneo, Ceratitis capitata (Wied.), Díptera: Tephritidae, es una de las plagas agrícolas de mayor impacto a nivel mundial. Ataca los frutos de unas 400 especies de plantas de importancia agrícola. En los países donde está presente, como Guatemala, limita la producción y exportación hortofrutícola. La Planta El Pino, es la unidad de producción del Programa Moscamed Guatemala, cuyo propósito es mantener el estatus de las zonas internacionalmente reconocidas como libres de plaga, en Estados Unidos, México, Belice y Guatemala. En este estudio se documenta el proceso de tratamiento de aguas servidas en la Planta El Pino y se evalúa su impacto ambiental, según el acuerdo 236-2006 del Ministerio del Ambiente y Recursos Naturales. Los resultados obtenidos se comparan con los de dos comunidades cercanas e independientes. Se incluyen los resultados del estudio técnico sobre la calidad de aguas servidas, realizado en el 2017 y una encuesta para medir la percepción sobre el impacto social y ambiental de la organización en las comunidades de influencia.
\end{abstract}

\section{Palabras clave}

Moscamed, aguas servidas, lodos, impacto ambiental, tratamiento de aguas.

\begin{abstract}
The Mediterranean fruit fly, Ceratitis capitata (Wied.), Díptera: Tephritidae, is one of the most relevant agricultural pests worldwide. It affects the fruits of over 400 species of economically-important plants. In those countries where it is present, such as Guatemala, it severely limits the production and export of fruits and vegetables. El Pino facility is the production unit of the Guatemalan Medfly Program, whose main goal is to maintain the status of the internationally recognized pest-free areas in United States, Mexico, Belize and Guatemala. In this study, the treatment of spent water at El Pino is documented. Its environmental impact is evaluated, accordingly with the 236-2006 agreement by the Guatemalan Ministry of Environment and Natural Resources. The results obtained at El Pino are compared with those obtained at two close but independent communities. The results of the 2017 technical study on the quality of spent water are included, and a survey was conducted in order to measure the community perception on the social and environmental impact of the organization on the influence communities.
\end{abstract}

\section{Keywords}

Medfly, spent water, muds, environmental impact, water treatment 


\section{Introducción}

Según Ramírez-Santos et al., (2016), la mosca de la fruta denominada "mosca del Mediterráneo" o "moscamed" es una de las plagas agrícolas más importantes a nivel mundial. Afecta unas 400 especies de plantas hospedantes de importancia agrícola, muchas de ellas presentes en Guatemala. La especie fue descrita en 1824, por Wiedemann. De Meyer et al. (2002), establecen que es originaria del África tropical, conclusión que se apoya en estudios moleculares realizados por Gasparich et al. (1997).

Davies, Villablanca y Roderick (1999) proponen que, después de su origen en África, la moscamed migró a Europa (1842) y Australia (1893). Los primeros reportes en América son en Brasil (1901) y California (1929), en plantas de café (Coffea arabica L.). En 1955 se confirma su presencia en Centroamérica y, en 1975, en la frontera entre Guatemala y México. Esta es una plaga cosmopolita, es decir, de distribución mundial.

Debido a su impacto económico, se han establecido programas de erradicación (Hendrichs et al., 2002) que emplean técnicas de Manejo Integrado de Plagas en Áreas Extensas (MIP-AE). La Técnica del Insecto Estéril (TIE), es una combinación de prácticas de control de plagas, amigables al ambiente (Dyck et al., 2005). En el caso de la moscamed, la TIE consiste en liberar en campo grandes cantidades de machos esterilizados, que se aparean con hembras silvestres para evitar su reproducción. Se apoya en acciones complementarias, tales como las cuarentenas y el monitoreo de la plaga, mediante trampas.

El primer reporte de mosca del Mediterráneo en Guatemala se produce el 21 de abril de 1975. El 15 de noviembre de 1975, se firma el Convenio entre Guatemala y México. El 21 de febrero de 1977 se suscribe el Memorándum de entendimiento entre el Ministerio de Agricultura, Ganadería y Alimentación de Guatemala y el Departamento de Agricultura de los Estados Unidos. Las acciones que el Programa Moscamed realiza, tienen su base legal en el acuerdo gubernativo del 19 de mayo de 1975. Actualmente el programa opera bajo un con- venio firmado en mayo del 2014 por los gobiernos de Estados Unidos, México y Guatemala.

La Planta El Pino es la unidad de producción del Programa Moscamed Guatemala. Ubicada en Barberena, Santa Rosa, en latitud $14.33^{\circ} \mathrm{N}$ y longitud $90.44^{\circ} \mathrm{O}$, empezó a funcionar desde 1995. En junio de 1996 inicia la exportación de pupa de machos estériles hacia los Estados Unidos. Actualmente tiene una producción aproximada de 1,500 millones de machos estériles por semana (MOSCAMED, 2017). Sus productos incluyen: a) envíos de pupa de machos estériles hacia California y Florida, b) huevo tratado térmicamente hacia México y c) machos estériles adultos para su liberación en Guatemala.

Los procesos de la Planta El Pino requieren grandes cantidades de agua, que generan alrededor de 40,000 galones/día de aguas residuales. Para su tratamiento cuenta con una planta aeróbica de lodos activados y no realiza descargas directas a cuerpos receptores naturales, ni al alcantarillado (Zaldaño, 2018). Entre los años 2014 y 2016 cuenta con cuatro mediciones de los 20 parámetros requeridos en el acuerdo gubernativo No. 236-2006 del Ministerio de Ambiente y Recursos Naturales, "Reglamento de las descargas, reúso de aguas residuales y disposición de lodos". A finales del 2017, realizó el estudio técnico requerido por dicho acuerdo, el cual tiene una vigencia de 5 años.

La revolución industrial del siglo XVIII marcó el inicio del dilema de las aguas residuales industriales que enfrenta actualmente la sociedad (UNESCO, 2017). Los desechos químicos llegan a los cuerpos receptores naturales y contaminan los mantos freáticos (Etienne, 2009). Las aguas residuales son subproductos de la actividad humana, la cual es directamente proporcional a su crecimiento (Palomo, 2011). Aproximadamente el $80 \%$ de todas las enfermedades y una tercera parte de las defunciones de los países subdesarrollados, están asociadas al consumo de agua contaminada (OMS, 1998).

A diferencia de otros recursos naturales, el agua dulce no tiene sustituto: si se agota o no se le trata, se pierde (Cáceres, 2016). La escasez de agua potable se incrementa debido a las actividades huma- 
nas y el cambio climático. En las comunidades más pobres, las aguas residuales son el único recurso hídrico (FAO, 2013). El mal manejo de las aguas residuales puede tener consecuencias graves para la salud humana, el ambiente y el desarrollo económico (ONU, 2007). Las descargas directas de aguas servidas a cuerpos receptores naturales, amenazan la sostenibilidad y ponen en riesgo la salud de la población (Loose, 2015).

Según Reyes (2009), un contaminante es "cualquier sustancia o desecho, natural o artificial, que genera problemas al entorno natural, que puede dañar la calidad de la atmósfera, agua, suelo, aire o cualquier elemento ambiental y que tienen efectos nocivos para los seres vivos y el medio ambiente, y por consiguiente a la salud humana". Castillo (2006), se refiere a un contaminante como "cualquier agente ajeno o sustancia ajena a los componentes normales o naturales del medio ambiente".

En los últimos años, se han podido observar en Guatemala cómo se están contaminando las fuentes hídricas a un paso acelerado (Monterroso, 2008). Según Orantes (2015), el 95\% de los cuerpos receptores en Guatemala, presentan contaminación. Castillo (2018) realizó un estudio en el departamento de Huehuetenango, donde más del $54 \%$ del agua está contaminada por bacterias y se incumple la norma COGUANOR en un $73 \%$, lo que provocó 53 mil casos de diarrea en el 2017, de los cuales el $65 \%$ fueran niños. Se estima que entre el 2000 al 2017, este problema ha provocado 3,962 defunciones.

En el 2012, la Mina San Rafael fue denunciada por verter aguas residuales en la cuenca del río Los Esclavos. En el 2015 fue denunciada la empresa REPSA, por contaminar el río La Pasión (Orantes, 2015). En el 2016, Honduras reclama a Guatemala por la contaminación del río Motagua y de sus costas (Mosquera, 2016). En el Lago de Atitlán se ha documentado el desfogue de aguas servidas sin tratar (Sáenz, 2014). Estudios recientes por Romero (2013) concluyen que en el lago de Atitlán se descargan directamente 1.37 millones de $\mathrm{m}^{3}$ /año de aguas residuales.
A los problemas descritos sobre la contaminación, se suma el efecto del cambio climático. El Instituto de Investigación sobre el Cambio Climático, lo define como "una desviación súbita y significativa de los patrones de clima considerados normales, que puede ser por causas naturales o por la actividad del hombre". Otros autores lo definen como "todo cambio que ocurre en el clima, a través del tiempo, resultado de la variabilidad natural o de las actividades humanas" (SEMARNAT, 2009).

El cambio climático está provocando en las regiones templadas, cambios en las corrientes marinas, que se reflejan en las corrientes atmosféricas, lo cual está provocando inviernos más crudos y cambios en los patrones de lluvia que afectan a los cultivos y la provisión de agua potable. En las regiones tropicales, las tormentas y huracanes son más frecuentes y fuertes. Adicionalmente, las inundaciones, por el incremento del nivel del mar o por lluvias en exceso se han registrado a nivel mundial (Zaldaño, 2018).

El impacto de un clima anómalo o extremo es lo que ha llevado a los expertos a nivel mundial, a que se enfoquen en el tema del cambio climático (Martínez y Fernández, 2004). Los efectos del cambio climático son inciertos, pero se estima que será responsable de incrementar la escasez de agua potable en un 20\% (Chaparro y Ovalles, 2017). Guatemala está incluida entre los diez países a nivel mundial con mayor riesgo o vulnerabilidad ante el impacto del cambio climático (Oglesby y Rowe, 2015).

\section{Metodología}

Para establecer el impacto ambiental de las aguas servidas en la Planta El Pino, se analizaron los resultados de las cuatro mediciones de los parámetros requeridos por el acuerdo 236-2006 del Ministerio de Ambiente y Recursos Naturales, "Reglamento de las descargas y reúso de aguas residuales y de la disposición de lodos", el cual establece límites permisibles para grasas y material flotante, color del agua, metales pesados, demanda bioquímica de oxígeno, fósforo, nitrógeno, pH, sólidos en 
suspensión y cargas de bacterias coliformes. Estos límites se van reduciendo con el tiempo.

Se analizaron las conclusiones del estudio técnico, realizado en diciembre del 2017, el cual mantiene su vigencia por cinco años. Las mediciones parciales deben hacerse dos veces por año, dependiendo de cuál de los escenarios cubiertos por dicho acuerdo aplica a la Planta El Pino, Moscamed (MARN, 2006):

a) Las aguas residuales son vertidas directamente a un cuerpo receptor natural, en cuyo caso, aplicarían los 20 parámetros (artículo 20).

b) La Planta El Pino es un ente generador nuevo. Requeriría una evaluación de impacto ambiental y aplicarían 18 requisitos (artículo 21).

c) Las aguas residuales se descargan en esteros (artículo 22), en cuyo caso aplican los 20 parámetros establecidos en el artículo 20.

d) Las aguas residuales se vierten pero no están conectadas al alcantarillado público, aplican 19 parámetros (artículo 23) y se reduce su tolerancia con el tiempo.

e) Las aguas residuales se vierten al alcantariIlado público, aplican 20 parámetros (artículo 25), su tolerancia se reduce con el tiempo (artículos 26 al 27) y requieren tratamientos previos a la descarga (artículos 31 al 33).

f) Las aguas residuales se reusan y pueden ser: de tipo I (riego agrícola general), tipo II (riego de productos agrícolas comestibles), tipo III (acuacultura), tipo IV (pastos y otros cultivos) y tipo $\vee$ (usos recreativos). Los límites se establecen en el artículo 35.

Finalmente y con el propósito de medir la percepción sobre el impacto social y ambiental de la Planta El Pino y sus aguas servidas, se realizó una encuesta a 49 personas, que representan el 50\% de los habitantes de la comunidad más cercana, "Mal País", sobre: a) género, edad, escolaridad y actividad principal, b) percepción de la comunidad respecto a Moscamed, problemas de salud, pérdidas económicas y uso del agua, beneficios y dificultades y c) relevancia de los temas relacionados con el uso del agua.

\section{Resultados}

Basado en los registros de la Planta El Pino se estableció que diariamente se generan alrededor de 40,000 galones de aguas servidas, provenientes de los procesos de cría masiva, las cuales son tratadas mediante una planta aeróbica de lodos activos y, a partir del 2017, el efluente es tratado mediante una lámpara UV que reduce las cargas de bacterias coliformes. Finalmente, el efluente tratado es vertido a una laguna artificial. Las aguas de lluvia son separadas desde el inicio y no se mezclan con las aguas grises provenientes de los procesos.

No se generan ni descargan biodesechos sólidos (lodos), con excepción de unos $150 \mathrm{Kg} / a n ̃ o ~ q u e$ provienen de la planta de tratamiento de aguas, que se compostean y se emplean como abono orgánico, a una razón promedio de $20 \mathrm{Kg} / \mathrm{ha}$, por debajo de las descargas permisibles establecidas por el acuerdo 236-2006, que pueden alcanzar las 10 ton/ha por año. El estudio técnico realizado en diciembre del 2017 incluye el análisis de dichos lodos, que cumplen con los límites permisibles.

La Planta El Pino no realiza descargas directas a cuerpos receptores naturales, ni al alcantarillado, y todos sus efluentes son tratados previo a su descarga, a diferencia de las comunidades aledañas que realizan descargas directas de aguas servidas no tratadas, a cuerpos receptores naturales (Zaldaño, 2018). Los resultados de las mediciones en los efluentes de la Planta El Pino, se resumen en la Tabla 1 y muestran un alto grado de cumplimiento. Se incluye una medición adicional, en octubre del 2017, que registra el contenido de bacterias coliformes (UFC/100 ml), después de la instalación de la lámpara UV en el efluente de la planta de tratamiento de aguas servidas. 
Tabla 1

Resultados de los análisis de descargas de aguas residuales de la planta de tratamiento, Planta El Pino, Moscamed

\begin{tabular}{|c|c|c|c|c|c|c|c|c|}
\hline \multirow[b]{2}{*}{ Análisis } & \multirow[b]{2}{*}{ Unidad } & \multicolumn{4}{|c|}{ Resultados del análisis del efluente } & \multicolumn{3}{|c|}{ Límites } \\
\hline & & sep-14 & nov-15 & may-16 & dic-16 & $\begin{array}{l}\text { mayo } \\
2015\end{array}$ & $\begin{array}{l}\text { mayo } \\
2020\end{array}$ & $\begin{array}{l}\text { mayo } \\
2024\end{array}$ \\
\hline Grasas y aceites & $\mathrm{mg} / \mathrm{L}$ & $<5$ & $<5$ & $<5$ & $<5$ & 50 & 25 & 10 \\
\hline Material flotante & - & 0 & 0 & 0 & 0 & 0 & 0 & 0 \\
\hline Arsénico & $\mathrm{mg} / \mathrm{L}$ & $<0.0025$ & $<0.0020$ & $<0.0020$ & 0.0041 & 0.1 & 0.1 & 0.1 \\
\hline Cadmio & $\mathrm{mg} / \mathrm{L}$ & $<0.012$ & $<0.0080$ & $<0.0080$ & $<0.0090$ & 0.1 & 0.1 & 0.1 \\
\hline Cianuro & $\mathrm{mg} / \mathrm{L}$ & $<0.010$ & $<0.010$ & $<0.010$ & $<0.010$ & 1 & 1 & 1 \\
\hline Cobre & $\mathrm{mg} / \mathrm{L}$ & $<0.035$ & $<0.040$ & $<0.040$ & $<0.040$ & 3 & 3 & 3 \\
\hline Cromo VI & $\mathrm{mg} / \mathrm{L}$ & $<0.010$ & $<0.010$ & $<0.010$ & $<0.010$ & 0.1 & 0.1 & 0.1 \\
\hline Mercurio & $\mathrm{mg} / \mathrm{L}-\mathrm{Hg}$ & $<0.00065$ & $<0.00065$ & $<0.00095$ & $<0.0012$ & 0.02 & 0.02 & 0.01 \\
\hline Níquel & $\mathrm{mg} / \mathrm{L}-\mathrm{Ni}$ & $<0.300$ & $<0.300$ & $<0.300$ & $<0.300$ & 2 & 2 & 2 \\
\hline Plomo & $\mathrm{mg} / \mathrm{L}-\mathrm{Pb}$ & $<0.060$ & $<0.060$ & $<0.060$ & $<0.070$ & 0.4 & 0.4 & 0.4 \\
\hline Zinc & $\mathrm{mg} / \mathrm{L}-\mathrm{Zn}$ & 0.071 & $<0.065$ & $<0.075$ & $<0.095$ & 10 & 10 & 10 \\
\hline Color & u Pt-Co & 272 & 87 & 61 & 54 & 1000 & 750 & 500 \\
\hline DBO & $\mathrm{mg} / \mathrm{L}-\mathrm{O} 2$ & 15 & $<10$ & $<10$ & 21 & - & - & 200 \\
\hline P total & $\mathrm{mg} / \mathrm{L}-\mathrm{P}$ & 6.3 & 6.7 & 12.05 & 5.7 & 30 & 15 & 10 \\
\hline $\mathrm{N}$ total & $\mathrm{mg} / \mathrm{L}$ & 13.5 & 6.89 & 9 & 8.7 & 50 & 25 & 20 \\
\hline $\mathrm{pH}$ & unidades & 7.46 & 7.76 & 7.55 & 7.62 & 6 a 9 & 6 a 9 & 6 a 9 \\
\hline $\begin{array}{l}\text { Sólidos en } \\
\text { suspensión }\end{array}$ & $\mathrm{mg} / \mathrm{L}$ & $<10$ & 16 & $<10$ & 12 & 400 & 150 & 100 \\
\hline $\begin{array}{l}\text { Coliformes } \\
\text { fecales }\end{array}$ & $\mathrm{NMP} / 100 \mathrm{ml}$ & 7,900 & 92,000 & 350,000 & 170,000 & $<1 \mathrm{E} 5$ & $<1 \mathrm{E} 4$ & $<1 \mathrm{E} 4$ \\
\hline
\end{tabular}

Fuente: Elaboración propia

La Tabla 1 muestra un alto grado de cumplimiento en los parámetros de calidad de aguas servidas, para los efluentes de la Planta El Pino, con excepción de las cargas de bacterias coliformes, que en el 2016 exceden el límite permisible. El análisis realizado en octubre del 2017, después de la instalación de la lámpara UV en el efluente de la plan- ta de tratamiento de aguas, muestra un $100 \%$ de cumplimiento en los parámetros establecidos por el acuerdo 236-2006. En comparación, los efluentes de las dos comunidades cercanas e independientes evaluadas (Tablas 2 y 3 ) muestran cargas de bacterias coliformes fuera del límite permisible. 
Tabla 2

Resultados de los análisis de descargas de aguas residuales de las comunidades cercanas al Río Naranjo, Santa Rosa

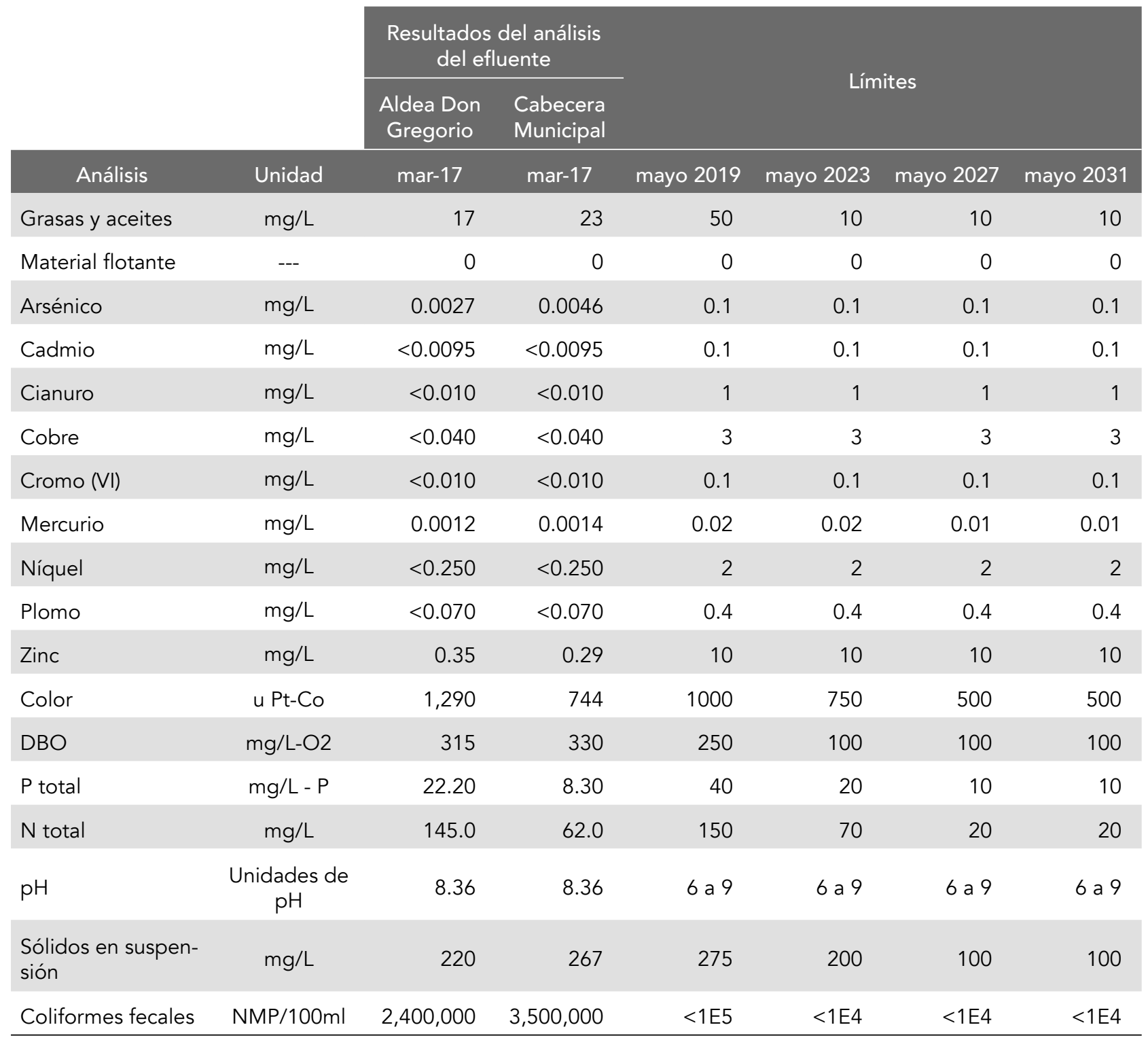

Fuente: Elaboración propia

Estos resultados muestran para las comunidades cercanas al Río El Naranjo, Santa Rosa, un menor grado de cumplimiento de los parámetros para descarga de aguas servidas a cuerpo receptor, establecidos en el acuerdo 236-2006, en especial en el contenido de bacterias coliformes fecales, que están entre 2.4 y 3.5 millones de UFC/100 ml, por lo que exceden el límite propuesto $(<100,000$ UFC/100 ml) en dicho decreto. 
Tabla 3

Resultados de los análisis de descargas de aguas residuales de la aldea El Cerinal, Barberena, Santa Rosa (Zaldaño, 2018)

\begin{tabular}{|c|c|c|c|c|c|c|}
\hline & & $\begin{array}{l}\text { Resultados } \\
\text { del análisis }\end{array}$ & & Límite & isibles & \\
\hline Análisis & Unidad & Mar-17 & $\begin{array}{l}\text { mayo } \\
2019\end{array}$ & $\begin{array}{l}\text { mayo } \\
2023\end{array}$ & $\begin{array}{l}\text { mayo } \\
2027\end{array}$ & $\begin{array}{l}\text { mayo } \\
2031\end{array}$ \\
\hline Grasas y aceites & $\mathrm{mg} / \mathrm{L}$ & 36 & 50 & 10 & 10 & 10 \\
\hline Material flotante & --- & 0 & 0 & 0 & 0 & 0 \\
\hline Arsénico & $\mathrm{mg} / \mathrm{L}$ & $<0.0015$ & 0.1 & 0.1 & 0.1 & 0.1 \\
\hline Cadmio & $\mathrm{mg} / \mathrm{L}$ & $<0.0095$ & 0.1 & 0.1 & 0.1 & 0.1 \\
\hline Cianuro & $\mathrm{mg} / \mathrm{L}$ & $<0.010$ & 1 & 1 & 1 & 1 \\
\hline Cobre & $\mathrm{mg} / \mathrm{L}$ & $<0.040$ & 3 & 3 & 3 & 3 \\
\hline Cromo (VI) & $\mathrm{mg} / \mathrm{L}$ & $<0.010$ & 0.1 & 0.1 & 0.1 & 0.1 \\
\hline Mercurio & $\mathrm{mg} / \mathrm{L}$ & 0.0014 & 0.02 & 0.02 & 0.01 & 0.01 \\
\hline Níquel & $\mathrm{mg} / \mathrm{L}$ & $<0.250$ & 2 & 2 & 2 & 2 \\
\hline Plomo & $\mathrm{mg} / \mathrm{L}$ & $<0.070$ & 0.4 & 0.4 & 0.4 & 0.4 \\
\hline Zinc & $\mathrm{mg} / \mathrm{L}$ & 0.298 & 10 & 10 & 10 & 10 \\
\hline Color & u Pt-Co & 428 & 1000 & 750 & 500 & 500 \\
\hline DBO & mg/L-O2 & 900 & 250 & 100 & 100 & 100 \\
\hline Fósforo total & $\mathrm{mg} / \mathrm{L}-\mathrm{P}$ & 15.90 & 40 & 20 & 10 & 10 \\
\hline Nitrógeno total & $\mathrm{mg} / \mathrm{L}$ & 86 & 150 & 70 & 20 & 20 \\
\hline $\mathrm{pH}$ & Unidades & 7.06 & 6 a 9 & 6 a 9 & 6 a 9 & 6 a 9 \\
\hline Sólidos en suspensión & $\mathrm{mg} / \mathrm{L}$ & 420 & 275 & 200 & 100 & 100 \\
\hline Coliformes fecales & $\mathrm{NMP} / 100 \mathrm{ml}$ & $13,000,000$ & $<1 \mathrm{E} 5$ & $<1 \mathrm{E} 4$ & $<1 \mathrm{E} 4$ & $<1 \mathrm{E} 4$ \\
\hline
\end{tabular}

Fuente: Elaboración propia

Estos resultados muestran para la comunidad de El Cerinal, Barberena, Santa Rosa, un menor grado de cumplimiento de los parámetros para descarga de aguas servidas a cuerpo receptor, establecidos en el acuerdo 236-2006, en especial en el contenido de bacterias coliformes fecales, que están en 13 millones de UFC/100 ml, el más alto registrado en este estudio, que exceden el límite propuesto $(<100,000$ UFC/100 ml) en dicho decreto.

El estudio técnico realizado en diciembre del 2017 establece que la Planta El Pino no realiza descar- gas de aguas residuales a cuerpo receptor natural, esteros o alcantarillados. Tampoco es un ente generador nuevo. Concluye que aplican los criterios para reuso de aguas residuales de tipo $\vee$ (uso recreativo), por lo que los parámetros a monitorear, dos veces por año, mientras este estudio técnico tenga vigencia (hasta dic-2022), son: demanda bioquímica de oxígeno, coliformes fecales y metales pesados; los límites se establecen en el artículo 35 del acuerdo 236-2006. 
El estudio técnico confirma los resultados obtenidos en las mediciones preliminares realizadas entre el 2014 al 2017, en el efluente de la planta de tratamiento de aguas servidas de la Planta El Pino: actualmente se encuentra en un cumplimiento del $100 \%$ de los parámetros establecidos en el acuerdo 236-2006. Por tanto, concluye que no se evidenció un impacto ambiental negativo de las aguas servidas de la Planta El Pino, cuya calidad excede la normativa ambiental vigente, desde los límites actuales hasta los que entrarán en vigor en mayo del 2030.

Los resultados de la encuesta realizada en la comunidad de Mal País, Barberena, Santa Rosa, se muestran en las Figuras 1 a 4 . Un $85.71 \%$ de los encuestados son mujeres. El $63.26 \%$ se encuentran en edades comprendidas entre los 14 a 40 años.
Un 49\% no tienen ninguna escolaridad y $31 \%$ sólo han completado la educación primaria. Un $76 \%$ de las encuestadas son amas de casa y un $10 \%$ albañiles, el resto se dedica a actividades diversas que incluyen: mecánica, agricultura, estudio y docencia, religión y enfermería.

La Figura 1 muestra que la mayoría de los encuestados (73\%) no conoce el trabajo que realiza El Pino. Un 35\% de los encuestados tiene familiares trabajando allí. Un 73\% está de acuerdo en que la Planta esté cerca de su comunidad. La Figura 2 indica que el $59 \%$ de los encuestados no manifiesta ningún problema de salud; los problemas estomacales, respiratorios u otros, no los relacionan con problemas de aguas servidas. Ninguno utiliza agua de los ríos vecinos. El 16\% declaran problemas con sus animales, que no relacionan con la calidad del agua.

Figura 1.

Percepción de la comunidad hacia la Planta El Pino Moscamed

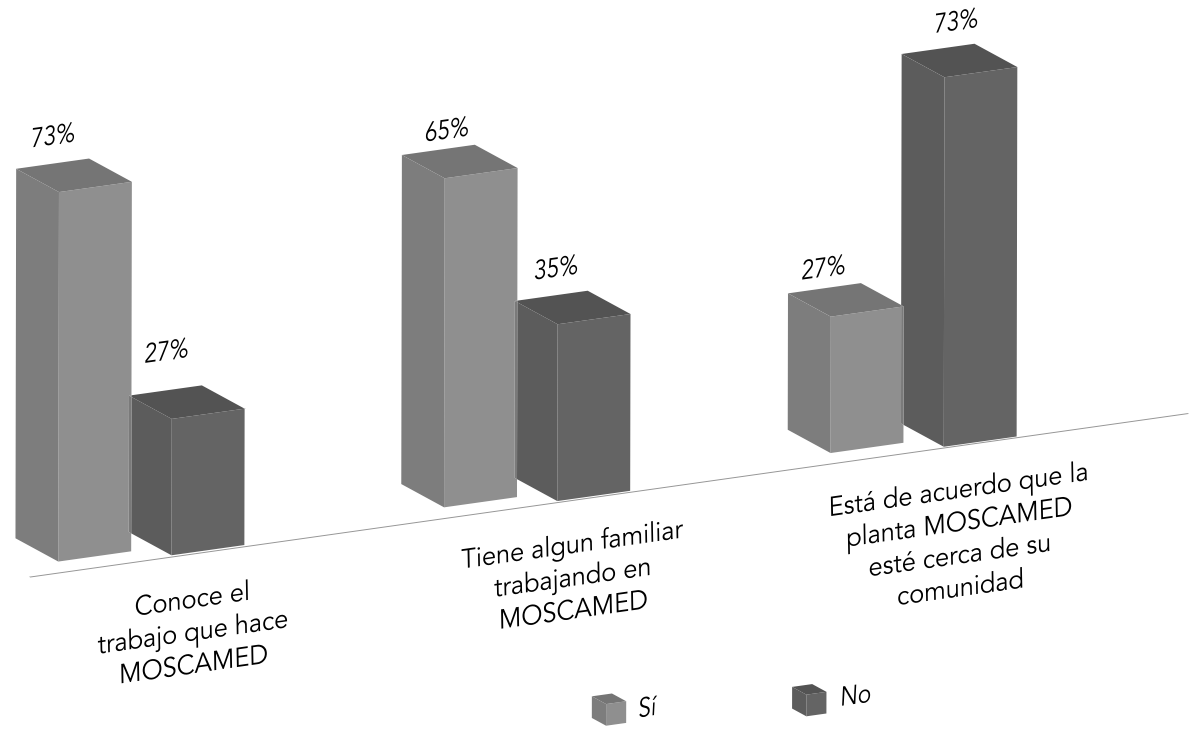

Fuente: Elaboración propia 
Figura 2.

Percepción de la comunidad hacia problemas de salud, económicos y uso del agua

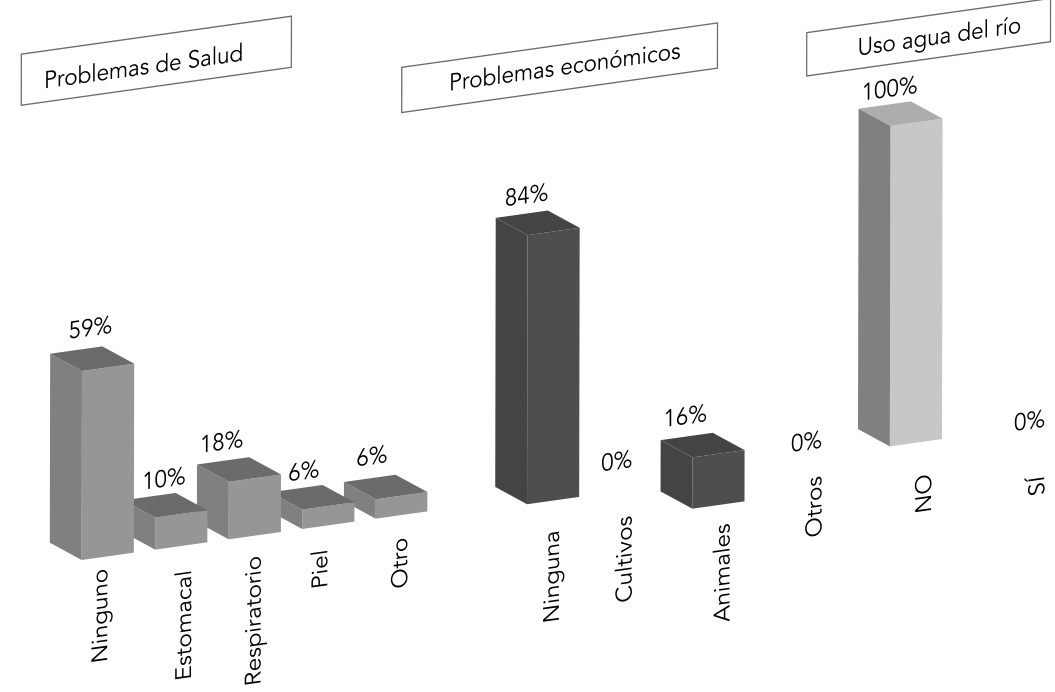

Fuente: Elaboración propia

La Figura 3 muestra que un $84 \%$ de las familias encuestadas no opinan o percibe beneficios de la Planta El Pino y un $94 \%$ no opina o percibe dificultades. En la comunidad, un $92 \%$ no opina o percibe beneficios y un $86 \%$ no opina o percibe dificultades. Un $6 \%$ de las familias identifica problemas de contaminación, a pesar de que el 99.99\% de todos los desechos de la Planta El Pino son reciclados, lo que apunta más a un problema de percepción y falta de divulgación, por parte de la Planta El Pino.

Figura 3.

Percepción de las familias y la comunidad sobre la Planta El Pino

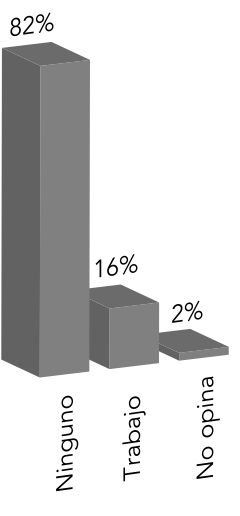

Beneficio

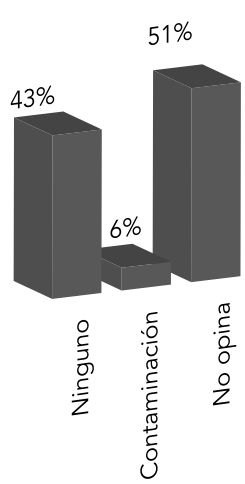

Dificultad

Familiar

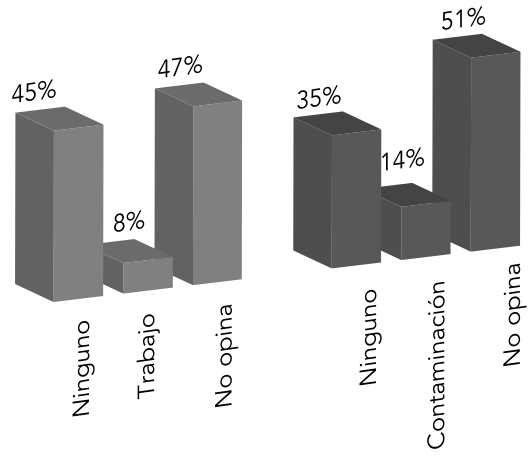

Beneficio
Dificultad

Comunidad

Fuente: Elaboración propia 
La Figura 4 muestra que los temas más relevantes, relacionados con el uso del agua, para la comunidad de Mal País, Barberena, Santa Rosa, son: a) el precio del agua (índice de 7.3) y b) la contamina- ción del agua (índice de 6.6). Temas como el conocimiento de la ley de aguas servidas (índice de 3.6) o el acceso al agua (índice de 4.5), fueron de interés bajo a medio.

Figura 4.

Índice promedio de relevancia de temas relacionados con el uso del agua, en la comunidad de Mal País. Desde 1=bajo hasta 10=alto.

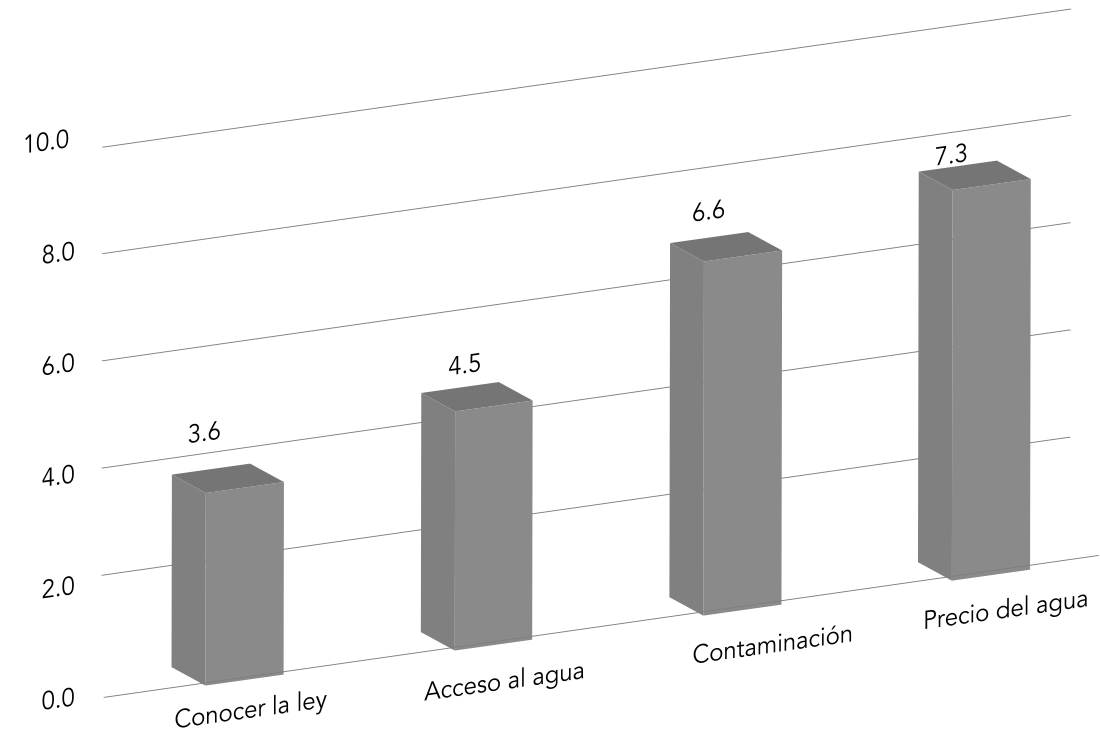

Fuente: Elaboración propia

\section{Análisis y Discusión}

Este estudio sugiere que las prácticas de manejo y tratamiento de sus aguas servidas han sido eficaces en mantener los efluentes de la Planta El Pino dentro de los límites establecidos por el acuerdo 2362006 del Ministerio del Ambiente y Recursos Naturales. Resultado confirmado por el estudio técnico de diciembre del 2017 y aceptado por el MARN, con un período de vigencia hasta diciembre del 2022, que muestra un $100 \%$ de cumplimiento, incluyendo los límites actuales y aquellos que entrarán en vigor en mayo del 2030.
La comparación con a) el río Naranjo en Santa Rosa y b) El Cerinal en Barberena, Santa Rosa, muestran que la calidad del agua en los efluentes en El Pino es superior al de dichas comunidades, especialmente en cuanto a cargas de bacterias coliformes fecales: en la última medición realizada en $\mathrm{El}$ Pino, en octubre del 2017 se registró $<10$ UFC/100 $\mathrm{ml}$. En comparación, la comunidad cercana al río Naranjo realiza descargas con 2.5-3.4 millones de UFC/100 ml y El Cerinal, 12 millones de UFC/100 $\mathrm{ml}$, por arriba del límite establecido en el acuerdo 236-2006 para el NMP de bacterias coliformes fecales $(<100,000$ UFC/100 ml). 
En cuanto a metales pesados, todos los efluentes analizados cumplen con la normativa legal establecida en el acuerdo 236-2006 y los niveles más bajos (por debajo del límite de detección de los aparatos analíticos) se registraron en los efluentes de la Planta El Pino, lo cual es un resultado positivo. Esto se debe probablemente al bajo nivel de actividades industriales de las comunidades analizadas.

Respecto a la percepción de la comunidad hacia las actividades de la Planta El Pino, hay un alto grado de aceptación en la comunidad encuestada, que es la más cercana, a pesar de que la mayoría de encuestados no trabajan para esta institución, ni reciben beneficios directos. La percepción de problemas ambientales o sociales provocados por la Planta El Pino es mínima. Existe la oportunidad de fortalecer las relaciones con las comunidades aledañas, mejorar la comunicación y divulgar los beneficios indirectos.

Es muy probable que el bajo nivel de escolaridad en la zona impida a las personas interesarse y conocer sobre los requisitos legales del recurso hídrico, incluyendo prácticas para el tratamiento de aguas servidas. Existe un conocimiento básico sobre el tema de contaminación del agua, pero sin un apoyo legal y medidas técnicas, difícilmente se podrá proteger y preservar este recurso. Este tema cobrará cada día más relevancia, debido al crecimiento de la población y a amenazas adicionales, tales como el cambio climático.

\section{Conclusiones}

Los parámetros analizados de la Planta de tratamiento de aguas residuales El Pino, cumplen con los límites permisibles de descargas de aguas residuales actuales, según el acuerdo 236-2006 del Ministerio de Ambiente y Recursos Naturales.

Las aguas residuales en la Planta El Pino presentan un mayor grado de cumplimiento de los parámetros monitoreados en el acuerdo 236-2006, comparado con las dos comunidades de referencia.
La comunidad encuestada percibe un impacto social y ambiental positivo de la Planta El Pino, Moscamed.

No se detectó un impacto ambiental negativo de las actividades de la Planta El Pino, Moscamed, relacionadas con el uso de agua y sus efluentes.

\section{Referencias}

Cáceres, V. (2016). Panorama actual en la gestión del agua y saneamiento en Argentina. Naturaleza, sociedad y ambiente. Académica y Cientifica. CUNSURORI, Volumen 3, pp. 77-94.

Castillo, H. (2006). La contaminación del agua de los ríos por los ingenios azucareros y su impacto en el medio ambiente, durante el tiempo de zafra o producción de azúcar en el municipio de Escuintla, departamento de Escuintla. Tesis, Guatemala: Facultad de Ciencias Jurídicas y Sociales, Universidad de San Carlos de Guatemala.

Castillo, M. (2018). "Consumen agua con bacterias" en Prensa Libre, 19 de enero 2018, p. 22.

Chaparro, F. y C. Ovalles (2017). Análisis del índice de riesgo de la calidad del agua para consumo humano -IRCA-y su relación con el clima y ubicación geográfica para el departamento del meta en los años 2012-2013. Tesis de Licenciatura. Colombia, Facultad de Ingeniería, Universidad de la Salle.

Davies N., Villablanca F. y G. Roderick. (1999). Determining the source of individuals: multilocus genotyping in nonequilibrium population genetics. Trends Ecol Evol. 1999, 14(1):17-21.

De Meyer, M., R. Copeland, R. Wharton and B. McPheron. (2002). On the geographic origin of the medfly. Proceedings of the 6th international fruit fly symposium. Stellenbosch, South Africa. 45-53. 
Dyck, V.A., Hendrichs, J. y Robinson, A.S. (2005). Sterile Insect Technique: Principles and Practice in Area-Wide Integrated Pest Management. Dordrecht, The Netherlands, Springer.

Etienne, G. (2009). Potabilización y tratamiento de agua. [En línea] Disponible en: http://www. bvsde.paho.org/bvsacg/fulltext/potabytrat. pdf [Último acceso: 14 Julio 2017].

FAO, (2013). Afrontar la escasez de agua. Un marco de acción para la agricultura y la seguridad alimentaria, Roma: FAO.

Gasparich, G., J. Silva, H. Han, B. Mcpheron, G. Steck and W. Sheppard. (1997). Population genetic structure of Mediterranean fruit fly (Diptera: Tephritidae) and implications for worldwide colonization patterns. Annals of the Entomological Society of America 90: 790-797.

Hendrichs, J., A. Robinson, J. Cayol and W. Enkerlin. (2002). Medfly area wide sterile insect techniques programmes for prevention, supression or eradication. Florida Entomologist, 85: 2-8.

Loose, D., (2015). Diagnóstico de las plantas de tratamiento de aguas residuales. En el ámbito de operación de las entidades prestadoras de servicios de saneamiento., Lima, Perú: Superintendencia Nacional de Servicios de Saneamiento SUNASS / Cooperación Alemana, GIZ.

MARN, (2006). Acuerdo gubernativo 236-2006. Reglamento de descargas y reuso de aguas residuales y de la disposición de lodos. Tipografía Nacional, Guatemala. 24 pp.

Martínez, J. y Fernández, A., (2004). Cambio climático: una visión desde México. Instituto Nacional de Ecología, México: Secretaría del medio ambiente y recursos naturales.

Monterroso, D., (2008). Proyecto de iniciativa de Ley general de aguas: Su utilización en las actividades agropecuarias. Investigación. Gua- temala: Dirección General de Investigación. Universidad de San Carlos de Guatemala.

MOSCAMED, (2017). Programa Moscamed Guatemala. [En línea] Disponible en: http://moscamed-guatemala.org.gt [Último acceso: 16 marzo 2017].

Mosquera, A., (2016). Sepultados por los desperdicios. Prensa Libre, 06 septiembre.

Oglesby, R. y Rowe, C. (2015). Informe final. Impactos climáticos para Guatemala: Resultados preliminares de los modelos climáticos regionales y globales IPCC AR5, Guatemala: Ministerio de Ambiente y Recursos Naturales - BID.

OMS, (1998). Guías para la calidad del agua potable. Vigilancia y control de los abastacemientos de agua de la comunidad. Ginebra: Organización Mundial de la Salud.

ONU, (2007). Gestión de aguas residuales, New York, USA: ONU.

Orantes, R. (2015). Un 95\% de los ríos y lagos del país está contaminado. Siglo 21, 21 junio del 2015.

Palomo Mahr, G. E., (2011). Irrigación de cultivos, una propuesta para la correcta disposición final de las aguas residuales tratadas., Guatemala: Facultad de Ingeniería, Universidad de San Carlos de Guatemala.

Ramírez-Santos, E., Rendón, P., Ruiz-Montoya, L., Toledo, J. y P. Liedo. (2016). Performance of a genetically modified strain of Mediterranean fruit fly (Díptera: Tephritidae) for area-wide integrated pest management with the sterile-insect technique. Journal of Economic Entomology, 2016, 1-11.

Reyes, R., (2009). Contaminación en el río Cahabón, Alta Verapaz, Guatemala. Estudio de las fuentes de contaminación. Tesis de Postgrado. Guatemala: Facultad de Arquitectura, Universidad de San Carlos de Guatemala. 
Romero, M. (2013). Caracterización de las aguas residuales generadas en la cuenca del lago de Atitlán y su impacto. Tesis de Postgrado. España, Escuela Politécnica Superior, Universidad Europea Miguel de Cervantes.

Sáenz, E. (2014). Identificarán fuentes que contaminan el lago de Atitlán. Prensa Libre, 13 marzo.

SEMARNAT, (2009). Cambio climático. Ciencia, evidencia y acciones, México: Secretaría de medio ambiente y recursos naturales.
UNESCO, (2017). Aguas residuales. El recurso desaprovechado, París, Francia: UNESCO ONU-Agua.

Zaldaño, O. (2018). Impacto ambiental y social de la planta de tratamiento de aguas residuales de la Planta El Pino en el sector rural del municipio de Barberena, Santa Rosa. Tesis de maestría. USAC, Guatemala. 92 pp. 
